\title{
Deep hypothermic circulatory arrest is not a risk factor for acute kidney injury in thoracic aortic surgery
}

\author{
Lars Englberger, MD, Rakesh M. Suri, MD, DPhil, Kevin L. Greason, MD, Harold M. Burkhart, MD, \\ Thoralf M. Sundt III, MD, Richard C. Daly, MD, and Hartzell V. Schaff, MD
}

\begin{abstract}
Objective: Previous studies describe a high incidence of acute kidney injury after open thoracic aortic surgery. Findings may be confounded by patient selection, including surgery with deep hypothermic circulatory arrest only or emergency procedures. We studied incidence and risk factors of acute kidney injury in patients undergoing thoracic aortic surgery.
\end{abstract}

\begin{abstract}
Methods: We reviewed 851 patients undergoing elective thoracic aortic surgery with and without deep hypothermic circulatory arrest between 2000 and 2007, focusing on clinical outcome and acute kidney injury defined by consensus RIFLE (Risk, Injury, Failure, Loss of function, End-stage renal disease) criteria.
\end{abstract}

\begin{abstract}
Results: Mean age was $59 \pm 16$ years; $29 \%$ were women. Surgical procedures included aortic root or ascending aorta in 817 patients (96\%), aortic arch in $172(20 \%)$, and descending thoracic aorta in $54(6 \%)$, with $20 \%$ reoperative procedures. Deep hypothermic circulatory arrest was used in $238(28 \%)$. Incidence of postoperative acute kidney injury (all RIFLE classes) was $17.7 \% ; 2.1 \%$ required renal replacement therapy. Mortality increased with RIFLE class severity of acute kidney injury $(P<.001)$. Independent risk factors for acute kidney injury were increased age, elevated body mass index, hypertension, impaired left ventricular ejection fraction, preoperative anemia, and cardiopulmonary bypass duration. Deep hypothermic circulatory arrest, aprotinin use, and preoperative creatinine level were not independently associated with acute kidney injury.
\end{abstract}

Conclusions: Thoracic aortic surgery can be performed with low rates of acute kidney injury, comparable to other cardiac surgical procedures. Deep hypothermic circulatory arrest and preoperative serum creatinine are not independent risk factors. RIFLE criteria allow comparison with previous studies and correlate well with patient outcome. Risk estimates for acute kidney injury require multivariable prediction. (J Thorac Cardiovasc Surg 2011;141:552-8)

Acute kidney injury (AKI) after thoracic aortic surgery is a frequent complication that is prognostically important. In recent reports that used the consensus RIFLE (Risk, Injury, Failure, Loss of function, End-stage renal disease) definition, ${ }^{1}$ the incidence of AKI has been approximately $50 \%$ among patients undergoing thoracic aortic surgery. ${ }^{2,3}$ Many previous studies have included patients undergoing aortic surgery with deep hypothermic circulatory arrest (DHCA) only, and others have featured heterogeneous patient cohorts including those undergoing emergency procedures, with a significant proportion of acute aortic dissections. Both aortic pathology and the clinical presentation of thoracic aortic emergencies significantly influence operative risk and outcome, particularly when preoperative organ malperfusion is present. These confounding effects suggest

From the Division of Cardiovascular Surgery, Mayo Clinic, Rochester, Minn.

L.E. received support from a grant of the Clinic for Cardiovascular Surgery, University Hospital Berne, Switzerland.

Disclosures: Authors have nothing to disclose with regard to commercial support.

Received for publication Nov 13, 2009; revisions received Jan 28, 2010; accepted for publication Feb 28, 2010; available ahead of print April 15, 2010.

Address for reprints: Hartzell V. Schaff, MD, Mayo Clinic, 200 First St SW, Rochester, MN 55905 (E-mail: schaff@mayo.edu).

$0022-5223 / \$ 36.00$

Copyright (c) 2011 by The American Association for Thoracic Surgery doi:10.1016/j.jtcvs.2010.02.045 that the higher incidence of AKI after thoracic aortic surgery relative to other types of cardiac surgery may not be a result of aortic surgery alone. In addition, potentially modifiable risk factors for AKI may be misestimated or not detected in heterogeneous study cohorts. This retrospective study was therefore designed to investigate incidence of and risk factors for AKI in patients undergoing elective surgery on the thoracic aorta with and without DHCA.

\section{MATERIALS AND METHODS Study Population}

After institutional review board approval (study-specific informed consent was waived), we investigated all patients who underwent elective thoracic aortic surgery with cardiopulmonary bypass (CPB) at the Mayo Clinic (Rochester, Minn) between January 2000 and December 2007. Patient data were recorded in a prospective computerized database according to the Society of Thoracic Surgeons Adult Database definitions. Patients with renal replacement therapy (RRT) before surgery were excluded, as were patients who underwent repair of the thoracoabdominal aorta. In accordance with Health Insurance Portability and Accountability Act guidelines, the few patients who denied access to their medical records for the purpose of research were not considered for analysis. Among patients who underwent multiple thoracic aortic procedures at our institution during the study period $(n=5)$, only data related to the first operation were included. Patients who died intraoperatively or within 24 hours postoperatively were excluded $(n=7)$, because no meaningful determination of postoperative AKI could be made in these cases. In addition to the available data in the clinical database, all electronic patient records were reviewed to obtain preoperative hemoglobin 


$$
\begin{aligned}
& \text { Abbreviations and Acronyms } \\
& \text { AKI = acute kidney injury } \\
& \text { BMI }=\text { body mass index } \\
& \text { CPB }=\text { cardiopulmonary bypass } \\
& \text { DHCA }=\text { deep hypothermic circulatory arrest } \\
& \text { GFR }=\text { glomerular filtration rate } \\
& \text { OR }=\text { odds ratio } \\
& \text { RIFLE }=\text { Risk, Injury, Failure, Loss of function, } \\
& \text { End-stage renal disease } \\
& \text { RRT }=\text { renal replacement therapy }
\end{aligned}
$$

level, the latest preoperative serum creatinine level, and serum creatinine level on each postoperative day to day 7, aprotinin use, and temperature during CPB. If multiple serum creatinine levels were measured per day, the highest recorded value was used for study purpose.

\section{Surgical Technique}

Surgical techniques,including site of aortic cannulation and additional selective cerebral perfusion during DHCA, and such other variables as temperature during $\mathrm{CPB}$ and aprotinin use were at the discretion of the operating surgeon. CPB was routinely instituted at 2.2 to $2.5 \mathrm{~L} /\left(\mathrm{min} \cdot \mathrm{m}^{2}\right)$. If DHCA was instituted, cooling was performed generally to a nasopharyngeal temperature of $16^{\circ} \mathrm{C}$ to $18^{\circ} \mathrm{C}$ or an isoelectric processes electroencephalogram, with bladder temperature less than $23^{\circ} \mathrm{C}$, because the cornerstone of cerebral protection remains profound hypothermia. More detailed information on surgical technique in patients undergoing thoracic aortic surgery with DHCA at our institution is outlined elsewhere. ${ }^{4}$

\section{Data definitions}

AKI was defined by the consensus RIFLE criteria ${ }^{1}$ according to the maximal change in serum creatinine level and glomerular filtration rate (GFR) during the first 7 postoperative days relative to baseline values before surgery. GFR was estimated with the simplified Modification of Diet in Renal Disease formula. ${ }^{5}$ The 3 thresholds for AKI severity according to RIFLE definitions are summarized in Table $1 .{ }^{1}$ We did not use urinary output criteria in defining AKI. All patients who met the RIFLE criteria for any class were classified as having AKI. Patients with AKI were stratified by RIFLE class according to serum creatinine level or GFR criteria within the first 7 postoperative days. All thresholds also included any patient who required RRT (intermittent hemodialysis or continuous venovenous hemofiltration) during the total postoperative hospital stay or within 30 postoperative days. Postoperative ventilation for longer than 24 hours was considered prolonged ventilation. Operative mortality was defined as in-hospital or 30-day mortality.

TABLE 1. Description of RIFLE definition criteria for acute kidney injury used in analysis ${ }^{1}$

\begin{tabular}{llll}
\hline & \multicolumn{3}{c}{ RIFLE class } \\
\cline { 2 - 4 } & \multicolumn{1}{c}{$\mathbf{R}$} & \multicolumn{1}{c}{ I } & \multicolumn{1}{c}{ F } \\
\hline Serum creatinine increase & $\geq 1.5$-fold & $\geq 2$-fold & $\geq 3$-fold \\
GFR decrease & $>25 \%$ & $>50 \%$ & $>75 \%$ \\
Serum creatinine level & & & $\geq 4 \mathrm{mg} / \mathrm{dL}$, acute \\
& & & rise $>0.5 \mathrm{mg} / \mathrm{dL}$ \\
\hline
\end{tabular}

One or more characteristics in a given column qualifies kidney failure for that class. RIFLE, Risk, Injury, Failure, Loss of function, End-stage renal disease; GFR, glomerular filtration rate.
TABLE 2. Surgical procedures performed in study cohort

\begin{tabular}{lrr}
\hline & No. & $\%$ \\
\hline Type of aortic surgery & & \\
Aortic root and/or ascending aorta only & 635 & $75 \%$ \\
Aortic root and/or ascending aorta plus arch & 156 & $18 \%$ \\
Aortic arch plus descending aorta & 35 & $4 \%$ \\
Aortic root and/or ascending aorta plus arch & 26 & $3 \%$ \\
$\quad$ and descending & & \\
Any concomitant surgery (CABG or valve surgery) & 712 & $84 \%$ \\
\hline$C A B G$, Coronary artery bypass grafting.
\end{tabular}

\section{Statistical Analysis}

Descriptive statistics for categoric variables are reported as frequency and percentage, whereas continuous variables are reported as mean $\pm \mathrm{SD}$ or median with range as appropriate. Categoric variables were compared among RIFLE classes with the $\chi^{2}$ test, and continuous variables were compared with analysis of variance or Kruskal-Wallis test as appropriate. Logistic regression models were used to find the univariate and multivariate predictors of AKI. The multivariate model considered univariately significant variables $(P<.05)$, with model selection through the stepwise method (backward and forward methods resulted in the same model). All statistical tests were 2-sided. Data were analyzed with SAS 9.1 software (SAS Institute, Inc, Cary, NC)

\section{RESULTS}

After the exclusion criteria were applied, the total study cohort consisted of 851 consecutive patients, median age 61 years (range 18-93 years). Of these patients, 244 $(29 \%)$ were women. Comorbidities included hypertension $(58 \%)$, diabetes $(8 \%)$, chronic lung disease $(12 \%)$, peripheral vascular disease $(9 \%)$, and cerebrovascular disease $(10 \%)$. With regard to aortic pathology, $63(7 \%)$ patients had Marfan syndrome and $46(5 \%)$ patients had chronic or subacute aortic dissection. Surgical procedures included the aortic root or ascending aorta in 817 patients $(96 \%)$, the aortic arch in $172(20 \%)$, and the descending thoracic aorta in $54(6 \%)$. Combined aortic operations and concomitant cardiac procedures are presented in Table 2. One hundred sixty-six patients $(20 \%)$ underwent reoperative procedures. In 238 cases $(28 \%)$, DHCA was used. Aprotinin was administered to 148 patients (17\%), and most others received tranexamic acid. Mean CPB time in the total study cohort was $118 \pm 58$ minutes, with an aortic crossclamp time of $81 \pm 42$ minutes. Twenty-one percent of patients with DHCA had a duration of arrest longer than 30 minutes.

With regard to preoperative renal status, 213 patients $(25 \%)$ had baseline serum creatinine levels greater than $1.2 \mathrm{mg} / \mathrm{dL}$, and $14(1.6 \%)$ had serum creatinine levels greater than $2.0 \mathrm{mg} / \mathrm{dL}$. Moderate reduction of GFR (31$\left.60 \mathrm{~mL} /\left[\mathrm{min} \cdot 1.73 \mathrm{~m}^{2}\right]\right)$ at baseline was present in $252 \mathrm{pa}-$ tients $(30 \%)$, and 13 patients $(1.5 \%)$ had severely decreased GFR $\left(\leq 30 \mathrm{~mL} /\left[\mathrm{min} \cdot 1.73 \mathrm{~m}^{2}\right]\right)$. Seven hundred patients $(82.3 \%)$ were free of postoperative AKI. One hundred fifty-one patients $(17.7 \%)$ were considered to have AKI: $107(12.5 \%)$ with RIFLE class R, 38 (4.5\%) with RIFLE 
TABLE 3. Patient characteristics by RIFLE class

\begin{tabular}{|c|c|c|c|c|c|}
\hline & \multirow[b]{2}{*}{ No AKI } & \multicolumn{3}{|c|}{ RIFLE class } & \multirow[b]{2}{*}{$P$ value } \\
\hline & & $\mathbf{R}$ & $\mathbf{I}$ & $\mathbf{F}$ & \\
\hline Patient population (no.) & $700(82.3 \%)$ & $107(12.5 \%)$ & $38(4.5 \%)$ & $6(0.7 \%)$ & \\
\hline \multicolumn{6}{|l|}{ Demographic data } \\
\hline Age $(y$, mean $\pm S D)$ & $57.3 \pm 16.3$ & $66.1 \pm 14.2$ & $66.1 \pm 12.3$ & $66.9 \pm 11.1$ & $<.001$ \\
\hline Sex (no. male) & $498(71.1 \%)$ & $76(71.0 \%)$ & $29(76.3 \%)$ & $4(66.6 \%)$ & .09 \\
\hline Body mass index $\left(\mathrm{kg} / \mathrm{m}^{2}\right.$, mean $\left.\pm \mathrm{SD}\right)$ & $28.0 \pm 5.4$ & $29.8 \pm 5.9$ & $28.5 \pm 6.6$ & $31.6 \pm 10.0$ & .01 \\
\hline \multicolumn{6}{|l|}{ Medical history } \\
\hline Diabetes (no.) & $48(6.9 \%)$ & $13(12.0 \%)$ & $4(10.5 \%)$ & $1(16.7 \%)$ & .19 \\
\hline Hypertension (no.) & $376(53.7 \%)$ & $82(76.6 \%)$ & $32(84.2 \%)$ & $6(100 \%)$ & $<.001$ \\
\hline Chronic lung disease (no.) & $70(10.0 \%)$ & $22(20.6 \%)$ & $7(18.4 \%)$ & $1(16.7 \%)$ & .03 \\
\hline Cerebrovascular disease (no.) & $60(8.6 \%)$ & $19(17.8 \%)$ & $7(18.4 \%)$ & $1(16.7 \%)$ & .01 \\
\hline Peripheral vascular disease (no.) & $55(7.9 \%)$ & $10(9.3 \%)$ & $8(21.1 \%)$ & $1(16.7 \%)$ & .07 \\
\hline \multicolumn{6}{|l|}{$\begin{array}{l}\text { Baseline (preoperative) renal function and hemoglobin } \\
\text { Creatinine }(\mathrm{mg} / \mathrm{dL})\end{array}$} \\
\hline Mean \pm SD & $1.14 \pm 0.26$ & $1.20 \pm 0.40$ & $1.17 \pm 0.26$ & $1.32 \pm 0.44$ & .75 \\
\hline$>1.2$ (no.) & $161(23.0 \%)$ & $38(35.5 \%)$ & $12(31.6 \%)$ & $2(33.35)$ & .03 \\
\hline Glomerular filtration rate $\left(\mathrm{mL} /\left[\mathrm{min} \cdot 1.73 \mathrm{~m}^{2}\right]\right)$ & & & & & .02 \\
\hline$>60$ (no.) & $499(71.3 \%)$ & $62(57.9 \%)$ & $22(57.9 \%)$ & $3(50 \%)$ & \\
\hline 31-60 (no.) & $192(27.4 \%)$ & $41(38.3 \%)$ & $16(42.1 \%)$ & $3(50 \%)$ & \\
\hline$\leq 30$ (no.) & $9(1.3 \%)$ & $4(3.7 \%)$ & 0 & 0 & \\
\hline Hemoglobin $(\mathrm{g} / \mathrm{dL}$, mean $\pm \mathrm{SD})$ & $14.0 \pm 1.6$ & $13.3 \pm 1.7$ & $13.1 \pm 1.9$ & $12.1 \pm 1.4$ & $<.001$ \\
\hline \multicolumn{6}{|l|}{ Preoperative cardiac status } \\
\hline Previous cardiac surgery (no.) & $122(17.4 \%)$ & $25(23.4 \%)$ & $17(44.7 \%)$ & $2(33.3 \%)$ & $<.001$ \\
\hline Previous myocardial infarction (no.) & $33(4.7 \%)$ & $6(5.6 \%)$ & $7(18.4 \%)$ & $2(33.3 \%)$ & $<.001$ \\
\hline Left ventricular ejection fraction $(\%$, mean \pm SD) & $60 \pm 10$ & $58 \pm 12$ & $57 \pm 11$ & $55 \pm 3$ & .06 \\
\hline Marfan syndrome (no.) & $57(8.1 \%)$ & $5(4.7 \%)$ & 0 & $1(16.7 \%)$ & .13 \\
\hline Aortic dissection (no.) & $36(5.1 \%)$ & $3(2.8 \%)$ & $5(13.2 \%)$ & $2(33.3 \%)$ & .002 \\
\hline \multicolumn{6}{|l|}{ Operative details } \\
\hline Aortic root and/or ascending aorta (no.) & $675(96.4 \%)$ & $102(95.3 \%)$ & $35(92.1 \%)$ & $5(83.3 \%)$ & .21 \\
\hline Aortic arch (no.) & $145(20.7 \%)$ & $19(17.8 \%)$ & $8(21.1 \%)$ & 0 & .56 \\
\hline Descending aorta (no.) & $41(5.9 \%)$ & $5(4.7 \%)$ & $7(18.4 \%)$ & $1(16.7 \%)$ & .01 \\
\hline Cardiopulmonary bypass duration (no.) & $112 \pm 53$ & $136 \pm 69$ & $164 \pm 72$ & $225 \pm 101$ & $<.001$ \\
\hline Crossclamp time (no.) & $78 \pm 41$ & $90 \pm 45$ & $97 \pm 42$ & $90 \pm 55$ & $<.001$ \\
\hline Circulatory arrest (no.) & $189(27 \%)$ & $33(30.8 \%)$ & $12(31.6 \%)$ & $4(66.7 \%)$ & .14 \\
\hline Circulatory arrest time $>30 \mathrm{~min}^{*}$ (no.) & $36(19.0 \%)$ & $6(18.2 \%)$ & $7(58.3 \%)$ & $2(50.0 \%)$ & .006 \\
\hline Temperature $\dagger\left({ }^{\circ} \mathrm{C}\right.$, mean $\left.\pm \mathrm{SD}\right)$ & $34.8 \pm 3.1$ & $34.1 \pm 2.7$ & $33.1 \pm 3.9$ & 16 & .001 \\
\hline Aprotinin (no.) & $114(16.3 \%)$ & $23(21.5 \%)$ & $10(26.3 \%)$ & $1(16.7 \%)$ & .27 \\
\hline \multicolumn{6}{|l|}{ Outcomes } \\
\hline Renal replacement therapy (no.) & 0 & $5(4.7 \%)$ & $8(21.1 \%)$ & $5(83.3 \%)$ & $<.001$ \\
\hline Mortality (no.) & $13(1.9 \%)$ & $4(3.7 \%)$ & $7(18.4 \%)$ & 0 & $<.001$ \\
\hline Prolonged ventilation $\ddagger$ (no.) & $51(7.3 \%)$ & $20(18.7 \%)$ & $24(63.2 \%)$ & $5(83.3 \%)$ & $<.001$ \\
\hline Hospital stay $\ddagger$ (d) & & & & & $<.001$ \\
\hline Mean $\pm \mathrm{SD}$ & $7.0 \pm 3.8$ & $9.9 \pm 7.9$ & $20.1 \pm 33.1$ & $45.3 \pm 34.2$ & \\
\hline Median & 6 & 8 & 12 & 32 & \\
\hline
\end{tabular}

class I, and $6(0.7 \%)$ with RIFLE class F. Demographic and operative variables of patients according to severity of RIFLE classification are presented in Table 3. There were significant differences between patients with no AKI and patients with any RIFLE class AKI in age, body mass index (BMI), hypertension, chronic lung disease, cerebrovascular disease, baseline serum creatinine level $(>1.2 \mathrm{mg} / \mathrm{dL})$, baseline GFR, preoperative hemoglobin, previous cardiac sur- gery, previous myocardial infarction, aortic dissection, surgery of the descending thoracic aorta, CPB duration, crossclamp time, duration of DHCA ( $>30$ minutes), and temperature during CPB (Table 3).

Eighteen patients $(2.1 \%)$ required RRT in the early postoperative period (during hospital stay or within 30 days). Mortality among patients who required postoperative RRT was $27.8 \%(\mathrm{n}=5)$, versus $2.3 \%(\mathrm{n}=19)$ among patients 
without postoperative RRT $(P<.001)$. Increased RIFLE class was associated with worse postoperative outcomes, such as need for RRT, prolonged intubation, longer hospital stay, and early mortality $(P<.001$ for each variable; Table 3$)$.

Table 4 shows results of univariate analyses of patient variables with and without AKI, independent of RIFLE class severity. In the multivariate logistic regression model, patient age, BMI, hypertension, left ventricular ejection fraction, preoperative hemoglobin, and CPB duration were all identified as independent predictors of postoperative AKI (Table 5). DHCA, aprotinin use, and preoperative serum creatinine level were not independently associated with AKI.

\section{DISCUSSION}

AKI after cardiac surgery is an important complication associated with adverse outcomes. Comparability of previous studies is limited because of variable definitions of AKI. The first consensus definition for AKI, named with the acronym RIFLE, was published by the Acute Dialysis Quality Initiative group in $2004 .{ }^{1}$ In a number of clinical studies, the RIFLE definitions have been found to be clinically useful for the diagnosis of AKI and its classification into different stages of severity. ${ }^{6,7}$ Two recent studies ${ }^{2,3}$ in which RIFLE criteria were applied in patients undergoing thoracic aortic surgery detected postoperative AKI in $48 \%$ and $55 \%$ of patients, respectively. Arnaoutakis and coworkers ${ }^{2}$ investigated a cohort of 267 patients undergoing aortic arch surgery, with DHCA used in all cases. Hobson and colleagues ${ }^{3}$ studied 2973 patients undergoing cardiothoracic surgery and found an incidence of AKI exceeding 50\% in a subgroup of 475 patients undergoing aortic surgery. Both of these studies demonstrated a clear association between postoperative AKI by RIFLE class and adverse outcome. Both studies, however, included urgent and emergency cases. Clinical presentation of thoracic aortic emergencies and heterogeneous patient groups have confounding effects on the incidence of AKI after thoracic aortic surgery; this is especially true for patients with acute aortic dissection when preoperative organ malperfusion is present. ${ }^{8,9}$ Consequently, our analysis was designed to determine incidence of and risk factors for postoperative AKI in a more homogenous group of patients undergoing elective thoracic aortic surgery with and without DHCA.

The main finding in our study was a relatively low incidence of postoperative AKI $(17.7 \%)$ relative to the results seen in the literature for patients undergoing thoracic aortic surgery. Indeed, rates of postoperative AKI according to the RIFLE definitions among our patients were comparable to published rates among nonselected consecutive patients undergoing various types of cardiac surgery $(19.3 \%)^{6}$ and nonselected patients after coronary artery bypass grafting $(26 \%))^{7}$ Our data demonstrate that elective thoracic aortic surgery can be performed with fairly low rates of postoperative AKI. The previous findings of a high incidence of AKI
TABLE 4. Univariate analysis of risk factors for acute kidney injury within all RIFLE classes $(\mathbf{n}=\mathbf{8 5 1})$

\begin{tabular}{|c|c|c|c|}
\hline Variable & $\begin{array}{l}\text { Odds } \\
\text { ratio }\end{array}$ & $\mathbf{9 5} \% \mathrm{CI}$ & $\begin{array}{c}P \\
\text { value }\end{array}$ \\
\hline Age & 1.04 & $1.03-1.05$ & $<.001$ \\
\hline Female sex & 0.95 & $0.64-1.41$ & .80 \\
\hline Body mass index & 1.05 & $1.02-1.08$ & .003 \\
\hline Diabetes & 1.84 & $1.04-3.26$ & .04 \\
\hline Hypertension & 3.34 & $2.19-5.09$ & $<.001$ \\
\hline Chronic lung disease & 2.23 & $1.39-3.57$ & $<.001$ \\
\hline Cerebrovascular disease & 2.32 & $1.42-3.80$ & $<.001$ \\
\hline Peripheral vascular disease & 1.69 & $0.97-2.94$ & .06 \\
\hline Baseline creatinine & 1.88 & $1.07-3.30$ & .03 \\
\hline Baseline creatinine $>1.2 \mathrm{mg} / \mathrm{dL}$ & 1.76 & $1.20-2.57$ & .004 \\
\hline Baseline GFR $>60 \mathrm{~mL} /\left(\min \cdot 1.73 \mathrm{~m}^{2}\right)$ & 0.39 & $0.12-1.3$ & .13 \\
\hline Baseline GFR $31-60 \mathrm{~mL} /\left(\min \cdot 1.73 \mathrm{~m}^{2}\right)$ & 0.7 & $0.21-2.36$ & .57 \\
\hline Preoperative hemoglobin & 0.75 & $0.67-0.83$ & $<.001$ \\
\hline Previous cardiac surgery & 1.95 & $1.30-2.91$ & .001 \\
\hline Previous myocardial infarction & 2.23 & $1.18-4.22$ & .01 \\
\hline Left ventricular ejection fraction & 0.98 & $0.96-0.99$ & .01 \\
\hline Marfan syndrome & 0.47 & $0.2-1.1$ & .08 \\
\hline Aortic dissection & 1.31 & $0.63-2.70$ & .47 \\
\hline Aortic root and/or ascending aorta surgery & 0.58 & $0.27-1.28$ & .18 \\
\hline Aortic arch surgery & 0.83 & $0.53-1.31$ & .43 \\
\hline Descending aorta surgery & 1.52 & $0.79-2.90$ & .21 \\
\hline Cardiopulmonary bypass duration & 1.01 & $1.01-1.01$ & $<.001$ \\
\hline Crossclamp time & 1.01 & $1.00-1.01$ & $<.001$ \\
\hline Circulatory arrest & 1.3 & $0.89-1.90$ & .18 \\
\hline Circulatory arrest* $>30 \mathrm{~min}$ & 1.88 & $0.92-3.81$ & .08 \\
\hline Temperature $\dagger$ & 0.91 & $0.86-0.97$ & .002 \\
\hline Aprotinin & 1.49 & $0.97-2.30$ & .07 \\
\hline
\end{tabular}

RIFLE, Risk, Injury, Failure, Loss of function, End-stage renal disease; $C I$, confidence interval. *Analysis of 238 patients with circulatory arrest. $†$ Patients operated without circulatory arrest.

among patients undergoing thoracic aortic surgery ${ }^{2,3,10}$ may have been confounded by patient selection. Thoracic aortic surgery in itself does not appear to increase risk of postoperative AKI relative to other cardiac surgical procedures performed with $\mathrm{CPB}$.

Nevertheless, our study confirms that AKI is a serious complication strongly associated with adverse outcome. This is true for the 3 threshold classes of RIFLE as well as

TABLE 5. Multivariate analysis of risk factors for acute kidney injury within all RIFLE classes $(\mathbf{n}=\mathbf{8 5 1})$

\begin{tabular}{lccr}
\hline \multicolumn{1}{c}{ Variable } & $\begin{array}{c}\text { Odds } \\
\text { ratio }\end{array}$ & $\mathbf{9 5 \%}$ CI & $\begin{array}{c}\boldsymbol{P} \\
\text { value }\end{array}$ \\
\hline Increased age (per 10 y) & 1.46 & $1.23-1.72$ & $<.001$ \\
Elevated body mass index (per 2 $\left.\mathrm{kg} / \mathrm{m}^{2}\right)$ & 1.13 & $1.05-1.21$ & .001 \\
Hypertension & 1.87 & $1.15-3.05$ & .012 \\
Higher left ventricular ejection fraction & 0.83 & $0.69-1.00$ & .046 \\
$\quad($ per 10\%) & & & \\
Higher preoperative hemoglobin (per 1 g/dL) & 0.85 & $0.75-0.95$ & .007 \\
Longer cardiopulmonary bypass (per 10 min) & 1.09 & $1.05-1.12$ & .001 \\
\hline RIFLE, Risk, Injury, Failure, Loss of function, End-stage renal disease; $C I$, confidence \\
interval.
\end{tabular}


for the most severe form of AKI requiring RRT (mortality among patients with postoperative RRT exceeded $20 \%$ ). These data support the earlier findings of Chertow and associates, ${ }^{11}$ who reported that renal failure requiring RRT after cardiac surgery is independently associated with mortality. As seen in Table 3, patients with postoperative RRT were found in all RIFLE classes, because RRT is only considered as an outcome (classes $\mathrm{L}$ and $\mathrm{E}$ ) in the original definition of RIFLE classification. ${ }^{1}$ Further, we identified all patients requiring RRT both in the hospital and through the initial 30 postoperative days, whereas AKI was defined by serum creatinine level and GFR changes within the first postoperative week.

Increasing severity of AKI also influenced other outcome variables (prolonged ventilation, hospital stay, and mortality). The association between outcome and postoperative AKI not only is important in predicting the early postoperative outcome but also has prognostic value for long-term outcome. In the study of Hobson and colleagues, ${ }^{3}$ longterm survival of patients with AKI was proportional to AKI severity, and the adjusted hazard ratio for patients with RIFLE class F (failure) was 2.14 relative to patients without AKI.

Because of safety concerns, aprotinin has been withdrawn from the market. ${ }^{12}$ During the study period, however, it was used in $17 \%$ of patients in our study cohort at discretion of the operating surgeon. In general, aprotinin was used more often for patients with an elevated risk of bleeding complications and for patients who were anticipated to require complex and prolonged surgical procedures. The effects of aprotinin on kidney function remain controversial. Despite a trend $(P=.07)$ toward a deleterious effect on the incidence of AKI in the univariate analysis, aprotinin was not independently associated with AKI in our patient cohort.

Interestingly, neither location of the aortic surgical procedure (aortic root or ascending aorta, aortic arch, descending aorta) nor use of DHCA was associated with AKI. This was true when analyzing distribution of patients within severity classes of AKI (only procedures at the descending aorta seem to have been associated with higher incidence of AKI) and in the univariate model comparing patients with and without AKI (all RIFLE classes). Our data document the safety of DHCA in aortic surgery, in contrast with other investigations that have identified DHCA as an independent risk factor for AKI with or without the need for RRT. ${ }^{13,14}$ These discrepant findings may be explained by the confounding factors introduced by studying heterogeneous patient groups, including patients operated on for acute aortic dissection or other aortic pathologies that adversely effect patient outcome.

Operations requiring DHCA are generally complex and prolonged, as demonstrated in our patient cohort. Patients operated on with DHCA had a significantly longer CPB time than did patients operated without DHCA $(156 \pm 60$ vs $104 \pm 50$ minutes, $P<.001)$. On the other hand, duration of $\mathrm{CPB}$ was identified as independent risk factor for AKI. These intuitively asymmetric results may be explained by the protective effects of profound DHCA on organ function, which counterbalance the kidney damage expected from prolonged $\mathrm{CPB}$. An interaction analysis of $\mathrm{CPB}$ time and DHCA supports our hypothesis (odds ratio [OR] 1.00, $95 \%$ confidence interval $0.92-1.07, P=.91$ ). It should be noted, however, that within the subgroup of patients operated on with DHCA, the incidence of AKI increased gradually with severity class of AKI when DHCA time exceeded 30 minutes (Table 3 ).

The independent association of AKI with increased age, hypertension, impaired left ventricular ejection fraction, and duration of CPB is not unexpected. The influence of BMI on outcome after cardiac surgery, however, is more complex. In analysis of a large retrospective cohort from the Society of Thoracic Surgeons database of patients undergoing coronary artery bypass grafting, Prabhakar and associates ${ }^{15}$ reported an increased incidence of renal failure among obese patients (OR 1.58 for BMI $35-40 \mathrm{~kg} / \mathrm{m}^{2}$ and OR 1.92 for BMI $\geq 40 \mathrm{~kg} / \mathrm{m}^{2}$ ). This finding was not confirmed by other clinical series. ${ }^{16-18}$ Again, comparability of studies is limited by various definitions of AKI and different patient populations. In our clinical series of patients undergoing elective thoracic aortic surgery, elevated BMI was found to be an independent risk factor for the development of AKI in the postoperative period.

Our finding that preoperative anemia is a risk factor for AKI is consistent with previous studies. ${ }^{7,19,20}$ In a recent multicenter study of a cohort of patients undergoing cardiac surgery with CPB, Karkouti and colleagues ${ }^{7}$ also found preoperative anemia to be independently associated with AKI within the 3 threshold classes of the RIFLE definition. Anemia contributes to AKI by reducing renal oxygen supply and may aggravate ischemia-reperfusion injury. Further studies are necessary, however, to determine whether low preoperative hemoglobin is a potentially modifiable risk factor or instead acts as a surrogate marker for severity of illness and comorbid status.

Several variables associated with postoperative AKI in the univariate analysis were not significant in the multivariate statistical model. Although a 2 -fold increased risk was detected in univariate analysis, reoperative surgery was not independently associated with postoperative AKI in our series of elective operations. This is similar to previous findings in a nonselected patient cohort undergoing aortic arch surgery. ${ }^{2}$ Patients with Marfan syndrome were less likely $(P=.08)$ to have postoperative AKI, which may be explained by the lower number of preoperative comorbidities generally seen in this population. Furthermore, patients with Marfan syndrome in our study population were significantly younger $(38 \pm 14$ vs $61 \pm 15$ years, $P<.001)$. 
Elevated preoperative creatinine values $(>1.2 \mathrm{mg} / \mathrm{dL})$ were associated with the development of postoperative AKI univariately but not in the multivariate model. This interesting finding is only partially explained by the definition of AKI with the RIFLE criteria, which are based on percentage changes in serum creatinine level or GFR. Twenty-five percent of patients in our elective cohort had baseline serum creatinine level greater than $1.2 \mathrm{mg} / \mathrm{dL}$, but only $1.6 \%$ had baseline serum creatinine level greater than $2.0 \mathrm{mg} / \mathrm{dL}$. Our conclusion may only be valid for patients with normal or mildly impaired renal function. It is well known, however, that there is a wide overlapping range in baseline creatinine values between patients who have postoperative AKI and who do not. ${ }^{21,22}$ In an additional statistical analysis, we have demonstrated the lack of significant collinearity between baseline creatinine and all other variables found to be independently associated with the occurrence of AKI. This finding emphasizes the need to estimate risk of postoperative AKI with multivariate prediction models, rather than by baseline serum creatinine level alone.

Our study has several potential limitations. First, we focused on preoperative and intraoperative variables that might predict AKI. Considering the complex interactions among different organ systems, the association between postoperative AKI and the identified risk factors may have been confounded by postoperative complications other than AKI. For example, in our study cohort the risk of AKI increased 3 -fold among patients who required re-exploration for bleeding (OR 3.1, 95\% confidence interval 1.8-5.3, $P<.001$ ). In this respect, a causal relation between AKI and outcome variables may be hypothesized but is not proved by our data. In addition, patients with prolonged intubation had a 6-fold increased risk of AKI (OR 6.1, 95\% confidence interval 3.9$9.5, P<.001)$. Several authors have described an interaction between mechanical ventilation and kidney function. ${ }^{23,24}$ There are many different reasons for prolonged ventilation, however, and AKI may cause prolonged ventilation or vice versa. Indeed, there is increasing evidence that the kidney is not simply a passive bystander in multiorgan dysfunction. ${ }^{25}$

In conclusion, thoracic aortic surgery can be performed with low rates of AKI and does not appear to carry elevated risk of AKI relative to other types of cardiac surgery. Profound hypothermia in patients undergoing DHCA appears to have protective effects on kidney function. Use of the RIFLE definition system for AKI allows comparison with previous studies and shows good correlation with patient outcome within the 3 threshold classes of AKI severity. Independent risk factors for AKI in patients undergoing thoracic aortic surgery are increased age, elevated BMI, hypertension, low left ventricular ejection fraction, preoperative anemia, and duration of CPB. Preoperative serum creatinine level, however, is not an independent risk factor for postoperative AKI, and estimates of AKI risk must to be based on multivariable prediction.
We thank Zhuo Li for expert statistical analysis and Judy Lenoch for assistance with the cardiovascular database that formed the basis for our study.

\section{References}

1. Bellomo R, Ronco C, Kellum JA, Mehta RL, Palevsky P. Acute Dialysis Quality Initiative workgroup. Acute renal failure-definition, outcome measures, animal models, fluid therapy and information technology needs: the Second International Consensus Conference of the Acute Dialysis Quality Initiative (ADQI) Group. Crit Care. 2004;8:R204-12.

2. Arnaoutakis GJ, Bihorac A, Martin TD, Hess PJ Jr, Klodell CT, Ejaz AA, et al. RIFLE criteria for acute kidney injury in aortic arch surgery. J Thorac Cardiovasc Surg. 2007;134:1554-61

3. Hobson CE, Yavas S, Segal MS, Schold JD, Tribble CG, Layon AJ, et al. Acute kidney injury is associated with increased long-term mortality after cardiothoracic surgery. Circulation. 2009;119:2444-53.

4. Sundt TM 3rd, Orszulak TA, Cook DJ, Schaff HV. Improving results of open arch replacement. Ann Thorac Surg. 2008;86:787-96.

5. Levey AS, Greene T, Kusek JW, Beck GL. MDRD Study Group. A simplified equation to predict glomerular filtration rate from serum creatinine [abstract]. $J$ Am Soc Nephrol. 2000;11:155A.

6. Kuitunen A, Vento A, Suojaranta-Ylinen R, Pettilä V. Acute renal failure after cardiac surgery: evaluation of the RIFLE classification. Ann Thorac Surg. 2006;81:542-6.

7. Karkouti K, Wijeysundera DN, Yau TM, Callum JL, Cheng DC, Crowther M, et al. Acute kidney injury after cardiac surgery: focus on modifiable risk factors. Circulation. 2009;119:495-502.

8. Augoustides JG. RIFLE criteria in aortic arch surgery: the further role of surgical subgroup [letter]. J Thorac Cardiovasc Surg. 2008;136:233.

9. Geirsson A, Szeto WY, Pochettino A, McGarvey ML, Keane MG, Woo YJ, et al. Significance of malperfusion syndromes prior to contemporary surgical repair for acute type A dissection: outcomes and need for additional revascularizations. Eur J Cardiothorac Surg. 2007;32:255-62.

10. Augoustides JG, Pochettino A, Ochroch EA, Cowie D, Weiner J, Gambone AJ, et al. Renal dysfunction after thoracic aortic surgery requiring deep hypothermic circulatory arrest: definition, incidence, and clinical predictors. J Cardiothorac Vasc Anesth. 2006;20:673-7.

11. Chertow GM, Levy EM, Hammermeister KE, Grover F, Daley J. Independent association between acute renal failure and mortality following cardiac surgery. Am J Med. 1998;104:343-8.

12. Ray WA, Stein CM. The aprotinin story-is BART the final chapter? [letter]. $N$ Engl J Med. 2008;358:2398-400.

13. Gaudino M, Luciani N, Giungi S, Caradonna E, Nasso G, Schiavello R, et al. Different profiles of patients who require dialysis after cardiac surgery. Ann Thorac Surg. 2005;79:825-9.

14. Zanardo G, Michielon P, Paccagnella A, Rosi P, Caló M, Salandin V, et al. Acute renal failure in the patient undergoing cardiac operation. Prevalence, mortality rate, and main risk factors. J Thorac Cardiovasc Surg. 1994;107:1489-95.

15. Prabhakar G, Haan CK, Peterson ED, Coombs LP, Cruzzavala JL, Murray GF. The risks of moderate and extreme obesity for coronary artery bypass grafting outcomes: a study from the Society of Thoracic Surgeons' database. Ann Thorac Surg. 2002;74:1125-30.

16. Reeves BC, Ascione R, Chamberlain MH, Angelini GD. Effect of body mass index on early outcomes in patients undergoing coronary artery bypass surgery. $J$ Am Coll Cardiol. 2003;42:668-76.

17. Rahmanian PB, Adams DH, Castillo JG, Chikwe J, Bodian CA, Filsoufi F. Impact of body mass index on early outcome and late survival in patients undergoing coronary artery bypass grafting or valve surgery or both. Am J Cardiol. 2007;100: 1702-8.

18. Villavicencio MA, Sundt TM 3rd, Daly RC, Dearani JA, McGregor CG, Mullany CJ, et al. Cardiac surgery in patients with body mass index of 50 or greater. Ann Thorac Surg. 2007;83:1403-11.

19. De Santo L, Romano G, Della Corte A, de Simone V, Grimaldi F, Cotrufo M, et al Preoperative anemia in patients undergoing coronary artery bypass grafting predicts acute kidney injury. J Thorac Cardiovasc Surg. 2009;138:965-70.

20. Kulier A, Levin J, Moser R, Rumpold-Seitlinger G, Tudor IC, Snyder-Ramos SA et al. Impact of preoperative anemia on outcome in patients undergoing coronary artery bypass graft surgery. Circulation. 2007;116:471-9.

21. Metha RH, Grab JD, O'Brien SM, Bridges CR, Gamme JS, Haan CK, et al. Bedside tool for predicting the risk of postoperative dialysis in patients undergoing cardiac surgery. Circulation. 2006;114:2208-16. 
22. Thakar CV, Arrigain S, Worley S, Yared JP, Paganini EP. A clinical score to predict acute renal failure after cardiac surgery. J Am Soc Nephrol. 2005;16: $162-8$.

23. Vieira JM Jr, Castro I, Curvello-Neto A, Demarzo S, Caruso P, Pastore L Jr, et al. Effect of acute kidney injury on weaning from mechanical ventilation in critically ill patients. Crit Care Med. 2007;35:184-91.
24. Ventilation with lower tidal volumes as compared with traditional tidal volumes for acute lung injury and the acute respiratory distress syndrome. The Acute Respiratory Distress Syndrome Network. N Engl J Med. 2000;342:1301-8.

25. Van Biesen W, Lameire N, Vanholder R, Mehta R. Relation between acute kidney injury and multiple-organ failure: the chicken and the egg question [letter]. Crit Care Med. 2007;35:316-7.

Access to The Journal of Thoracic and Cardiovascular Surgery Online is reserved for print subscribers!

Full-text access to The Journal of Thoracic and Cardiovascular Surgery Online is available for all print subscribers. To activate your individual online subscription, please visit The Journal of Thoracic and Cardiovascular Surgery Online, point your browser to http://www.mosby.com/jtcvs, follow the prompts to activate your online access, and follow the instructions. To activate your account, you will need your subscriber account number, which you can find on your mailing label (note: the number of digits in your subscriber account number varies from 6 to 10). See the example below in which the subscriber account number has been circled:

\section{Sample mailing label}

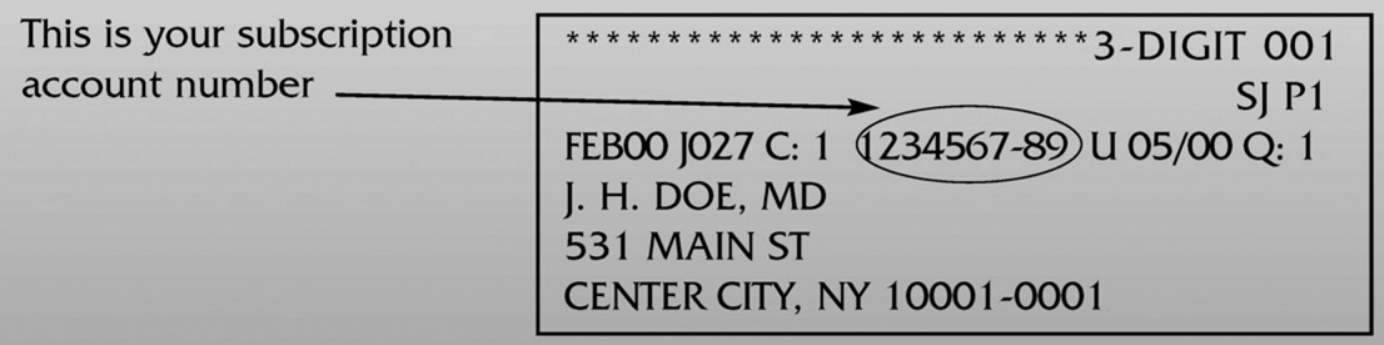

Personal subscriptions to The Journal of Thoracic and Cardiovascular Surgery Online are for individual use only and may not be transferred. Use of The Journal of Thoracic and Cardiovascular Surgery Online is subject to agreement to the terms and conditions as indicated online. 